ORIGINAL ARTICLE / ARTIGO ORIGINAL

\title{
Discrimination and common mental disorders of undergraduate students of the Universidade Federal de Santa Catarina
}

\author{
Discriminação e sofrimento psíquico de graduandos da Universidade \\ Federal de Santa Catarina
}

Maria Vitória Cordeiro de Souza', Isabel Lemkuhl', João Luiz Bastos"

\begin{abstract}
Introduction: The pathogenic and consistent effect of discrimination on mental health has been largely documented in the literature. However, there are few studies measuring multiple types of discrimination, evaluating the existence of a dose-response relationship or investigating possible effect modifiers of such an association. Objective: To investigate the association between experiences of discrimination attributed to multiple reasons and common mental disorders, including the adjustment for potential confounders, assessment of dose-response relations, and examination of effect modifiers in undergraduate students from southern Brazil. Methods: In the first semester of 2012, 1,023 students from the Universidade Federal de Santa Catarina answered a self-administered questionnaire on socio-demographic characteristics, undergraduate course, experiences of discrimination and common mental disorders. Associations were analyzed through logistic regression models, estimation of Odds Ratios and 95\% confidence intervals (95\%CI). Results: The study results showed that students reporting discrimination at high frequency and intensity were $4.4(95 \% \mathrm{CI} 1.6-12.4)$ times more likely to present common mental disorders. However, the relationship between discrimination and common mental disorders was protective among Electrical Engineering students, when compared to Accounting Sciences students who did not report discrimination. Conclusion: The findings suggest that the dose-response relationship between experiences of discrimination and common mental disorders reinforces the hypothetical causal nature of this association. Nevertheless, the modification of effect caused by the undergraduate course should be considered in future studies for a better understanding and measurement of both phenomena.
\end{abstract}

Keywords: Social discrimination. Stress, psychological. Brazil. Students. Causality. Epidemiology.

ISchool of Dentistry, Universidade Federal de Santa Catarina - Florianópolis (SC), Brazil.

"Department of Public Health, Universidade Federal de Santa Catarina - Florianópolis (SC), Brazil.

Corresponding author: João Luiz Bastos. Universidade Federal de Santa Catarina. Centro de Ciências da Saúde. Campus Universitário, Trindade, CEP 88010-970, Florianópolis, SC, Brasil. E-mail: joao.luiz.epi@gmail.com

Conflict of interests: nothing to declare - Financial support: Research Dean (Funpesquisa)/2011 of the Universidade Federal de Santa Catarina, process No. 153.163 . 
RESUMO: Introdução: O efeito deletério e consistente das experiências discriminatórias sobre a saúde mental tem sido amplamente documentado na literatura. No entanto, são escassos os trabalhos que aferem múltiplos tipos de discriminação, avaliam a existência de relação dose-resposta ou investigam possíveis modificadores de efeito dessa associação. Objetivo: Investigar a associação entre experiências discriminatórias por múltiplos motivos e sofrimento psíquico, incluindo a avaliação de efeito dose-resposta, o ajuste para potenciais confundidores e o exame de modificadores de efeito em estudantes universitários do sul do Brasil. Métodos: No primeiro semestre de 2012, 1.023 graduandos da Universidade Federal de Santa Catarina responderam a um questionário autopreenchível sobre características sociodemográficas, curso de graduação, experiências discriminatórias e sofrimento psíquico. As associações foram analisadas com modelos de regressão logística, estimação de razões de chance e seus respectivos intervalos de confiança de 95\% (IC95\%). Resultados: Observou-se que estudantes que relataram sofrer discriminação em alta frequência e intensidade apresentaram 4,4 (IC95\% 1,6-12,4) vezes mais chance de apresentar sofrimento psíquico. Entretanto, a relação da discriminação com o sofrimento psíquico foi protetora em meio aos graduandos de Engenharia Elétrica, quando comparados aos de Ciências Contábeis não discriminados. Conclusão: A partir do estudo, concluiu-se que a relação dose-resposta entre experiências discriminatórias e sofrimento psíquico reforça a hipótese de natureza causal dessa associação. Contudo, a modificação de efeito ocasionada pelo curso de graduação deve ser considerada em investigações futuras para uma melhor compreensão de ambos os fenômenos e suas estratégias de mensuração.

Palavras-chave: Discriminação social. Estresse psicológico. Brasil. Estudantes. Causalidade. Epidemiologia.

\section{INTRODUCTION}

Discrimination is a social phenomenon, characterized by an unfair behavior towards members of a given group, not based on a supposed merit or reciprocity, but on the belonging to those social categories ${ }^{1}$. This phenomenon manifests itself through negative behaviors in relation to the victims or through actions which unfairly favor the group of the perpetrator, creating, maintaining or reinforcing patterns of inequality ${ }^{2}$.

Discriminatory experiences are considered a stress factor that may impact the overall health of their victims and which are relatively uncontrollable and unpredictable ${ }^{3}$. This negative impact on their health may occur in a direct way, resulting in mental disorders and reducing levels of well-being, or indirect, through physiological pathways, such as the release of hormones related to stress and the adoption of harmful behaviors towards health as a way of coping with these experiences ${ }^{3}$.

The magnitude of the discriminatory phenomenon as a mental health determinant may be observed in studies, such as the one by Suija et al. ${ }^{4}$, which found that the impact of discriminatory experiences on the occurrence of depression is higher than that caused by the history of child abuse. Pieterse et al. ${ }^{5}$, in a metanalysis evaluating 66 studies published between January 1996 and April 2011, observed a positive association between discriminatory 
experiences and psychological stress in African-American individuals, indicating that higher discrimination levels are related to an increase of approximately $20 \%$ in the probability of common mental disorders.

Specifically, Brazil is considered a country whose social relations are complex and of which miscegenation is a distinctive sociological aspect. Many studies on the subject claim that discrimination was and still is a social phenomenon of great importance for this specific sociocultural context ${ }^{6}$. In a study carried out in Salvador (BA), Santana et al. ${ }^{7}$ observed that children and adolescents who reported racial discrimination were twice more likely to have depression, when compared to those who were not discriminated against. Pavão et $\mathrm{al}^{8}{ }^{8}$, in a research conducted with adults in the city of Belo Horizonte (MG), concluded that individuals who suffered racial discrimination had 1.77 higher odds of being struck by depression than their non-discriminated peers.

Although the scientific literature on discrimination and health is growing, the studies concentrate specially in the United States, even when the health condition investigated is mental health ${ }^{9}$. Another aspect observed in Brazilian studies on the subject is the emphasis on racial discrimination and the tendency to analyze the different kinds of discrimination separately, disregarding the intersectionality and possible combined effects of its frequency and intensity on health. Particularly, Bastos et al. ${ }^{10}$ observed that those who suffered discriminatory experiences motivated simultaneously by social class, race and age had a 14 times higher odds of reporting common mental disorders, when compared to the nondiscriminated respondents, showing the importance of the other kinds of discrimination in relation to health. Particularly, the study was the only one conducted with college students, among all the other ones mentioned above.

Thus, studies assessing different types of discrimination in the Brazilian context are needed, as well as those addressing their relations to health, so that it is possible to better understand both phenomena. The objective of this study was to investigate the association between discriminatory experiences attributed to multiple reasons and common mental disorders, including the adjustment for potential confounders, the analysis of the doseresponse relations and the examination of effect modifiers of this association in college students in southern Brazil.

\section{METHODS}

This is a cross-sectional study, whose target population consisted of students enrolled in the first academic semester of 2012 of the Universidade Federal de Santa Catarina (UFSC), campus João David Ferreira Lima. Considering that this work is part of a broader investigation, the total number of individuals to be interviewed was determined by the study of associations which demanded one of the largest sample sizes; thus, the association between discriminatory experiences and self-rated general health was taken as reference among all other relations which could be evaluated by the research. The prevalence of 
poor self-rated general health among those not discriminated against was considered to be $4.5 \%$, the prevalence of poor self-rated general health among those discriminated against was deemed to be $13.7 \%$, overall prevalence of discrimination in the population of $73.0 \%$, $\beta$ error of 0.05 and $\alpha$ error of 0.01 , according to the data of a similar study, carried out in Rio de Janeiro, in $2010^{11}$. This calculation resulted in 959 individuals, a number which was expanded to 1,341 , after correction by the design effect of $1.58^{11}$, adding $10 \%$ for losses or refusals and the use of formula for the calculation of the sample for finite populations.

The population universe consisted of 19,963 students, based on the total of students enrolled at UFSC in the second academic semester of 2011. New courses, which did not have their curricula fully integrated in the period of field work, were not considered in the investigated population, leaving 70 eligible courses. Three fixed strata were created, according to the semesters of study in which the students were in (first year, middle stage and final year), resulting in an eligible population of 6,237 students. Considering an average of 79 students, per course, enrolled in the 3 strata previously mentioned, it was verified the need to include 15 courses in the sample to be studied. The selection process was by complex sampling, taking the undergraduate courses as primary sample units. Fifteen numbers were drawn, 3 of them belonging to repeated courses, which resulted in a total of 12, namely: Accounting, Law, Electrical Engineering, Mechanical Engineering, Chemical Engineering, Sanitary and Environmental Engineering, History, Pedagogy, Psychology, Dentistry, Medicine and Information Systems. The second stage referred to the classes of each one of the selected courses belonging to the predefined strata.

Data collection was performed through the use of a self-completed questionnaire, which included socioeconomic and demographic characteristics, common mental disorders, discriminatory experiences and information related to the undergraduate course. Common mental disorders were collected using the short version of the General Health Questionnaire (GHQ) $)^{12}$, whih consists of 12 questions on common mental disorders in the last two weeks, such as, for example: "Have you been feeling that it is difficult to overcome your difficulties?”. In turn, in order to evaluate discriminatory experiences, we used the Explicit Discrimination Scale (EDS) ${ }^{11}$, which consists of 18 questions on experiences of differential treatment in different domains throughout life, including, for example: "When attending stores, restaurants, have you ever been treated in an inferior way in relation to the other customers?". Then, the respondent was questioned on the frequency of this experience, its motivations (color/race, socioeconomic position, gender, age, religious orientation, among others), the level of discomfort and whether they have felt discriminated against in these situations. The validation study of the EDS instrument was carried out in a population similar to the one in the present study (Brazilian college students) ${ }^{11}$.

The fieldwork was preceded by a pre-test and pilot study with 17 and 43 students, respectively, who were not a part of the selected sample. An instruction manual was prepared, in order to standardize the way study participants were approached by the research team. The filling out of the questionnaires occurred in a classroom, after the signing of the Informed Consent 
form, during regular hours of the selected disciplines. On average, the questionnaire took 20 minutes to be filled out.

All questionnaires were reviewed according to the rules of correction predefined by the research team. The questions which had been answered incorrectly or inconsistently were corrected, such as, for example: when the participant initially would state not having been discriminated against, however, in the sequence, they signaled their motivation and the frequency of the differential treatment, as well as feeling discriminated against at the time, this was considered a case of discrimination. Contradictory answers of which it was not possible to identify the correct answer were considered as being cases of absence of discrimination. A double data entry was performed, with automatic checks for consistency and range, comparing the results of both entries. In this case, all differences were identified and corrected, by consulting the original questionnaires.

The data were organized, cleaned and analyzed in the Stata $\AA$ software, v.11.2, through the estimation of absolute and relative frequencies of the characteristics of the investigated sample, as well as the association of discriminatory experiences with common mental disorders, considering the weights and the complex sampling design. Common mental disorders were considered among the individuals who positively answered at least 3 out of 12 GHQ questions, the 2 answers with highest intensity ${ }^{13}$. Those who stated, through the EDS, having suffered differential treatment in at least 1 of the 18 situations approached and that considered these as discriminatory treatments, were classified as discriminated against.

The association between common mental disorders and the sociodemographic characteristics was analyzed as for the statistical significance through the Rao-Scott test. In turn, the association between discriminatory experiences and common mental disorders adjusted for confounding factors, was evaluated with conventional logistic regression models, estimating odds ratios and their respective $95 \%$ confidence intervals $(95 \% \mathrm{CI})$. The inclusion of variables in the models was gradual, beginning with the association between discrimination and common mental disorders in the first model, successively adjusting for more confounders in each subsequent model, following the order: color/race (White, yellow or Black, according to the Brazilian Institute of Geography and Statics); socioeconomic position (according to quintiles of the National Wealth Index ${ }^{14}$ ); gender (male/female); age (in categories of $16-19,20-22,23-27$ and $28-52$ years of age); undergraduate course (the 12 previously mentioned); semester of study (first, middle and last). All variables were kept in the final model, regardless of their association with the outcome or statistical significance.

In order to evaluate the dose-response relation between discrimination and common mental disorders, a score for discrimination was calculated, which varied from 0 to 45 in the sample ${ }^{11}$, increasing according the frequency and intensity of the discriminatory event. Exploratory analysis based on diagrams applying the techniques of splines and lowess were executed in order to examine the dose-response relation and, after different score categorizations, identify the one which best represents the association, while still avoiding sparse strata in the analysis. Thus, the discrimination score was categorized in score 0 (not discriminated against); score 1; score 2; score 3 and 4; score 5 to 7 ; score 8 to 
10 ; score $11+$. Next, a logistic regression model was built in order to evaluate the doseresponse relation of this discrimination score with common mental disorder, adjusting for the same confounders mentioned.

Finally, in order to explore possible effect modifiers of the relation between discrimination and common mental disorders, different logistic regression models were built considering each one of the remaining variables of the model as an interaction factor. Bicaudal probability values lower than $5 \%$ were considered statistically significant in all analysis. The study was approved by the Ethics Committee of Research with Human Beings of the Universidade Federal de Santa Catarina in 12/13/2011, under protocol number 459965.

\section{RESULTS}

From a total of 1,264 eligible students, 1,023 of them were interviewed, corresponding to a response rate of $80.9 \%$. Absence in the classroom at the moment of data collection and students who had heir enrollment suspended were the main reasons for losses. As shown in Table 1, the courses with the highest percentages of respondents were the ones of History (18.2\%), Accounting (10.2\%) and Chemical Engineering (10.1\%). Most part of the sample consisted of students of the first semester $(40.3 \%)$, males $(55.7 \%)$ and over a third of them were between 20 and 22 years of age (36.1\%). The self-declared whites added up to more than $84.0 \%$. Most students are part of the richest quintile of Santa Catarina, which indicates that they have a privileged socioeconomic profile, when compared to the rest of the population of the state. Approximately $66.0 \%$ of the interviewed reported some kind of discriminatory experience throughout life. In turn, 4 out of each 10 students had common mental disorders.

As may be observed in Table 2, the highest frequency of common mental disorders was in the courses of History (59.0\%), followed by Pedagogy (47.4\%) and Medicine (43.3\%). The students in the last semester of study $(43.2 \%)$ and women $(41.4 \%)$ had a higher frequency of common mental disorder, when compared to their peers. The same happened to students aged between 23 and 27 years, who presented a prevalence of $42.9 \%$ of common mental disorders. The ones self-declared Black reported a prevalence of common mental disorder inferior to the one presented by whites and Brown people. It was verified that the extreme socioeconomic groups had higher frequencies of common mental disorders than the intermediary ones. Among those who claimed to have suffered from discriminatory experiences, the prevalence of common mental disorders affected about $50.0 \%$ of them.

The model 1 of Table 3 indicates that the individuals who suffered discrimination presented $2.3(95 \% \mathrm{CI} 1.8-3.0)$ times more chance of reporting common mental disorders than their peers. After adjustment of this association for undergraduate course, semester of study, gender, age, color/race and socioeconomic position, it was verified that people who reported discrimination had 2.1 (95\%CI $1.6-2.7)$ times more chance of having common mental disorders than their peers. In Figure 1, it is possible to observe that the frequency of common mental disorders gradually increases from the lowest exposure levels, 
Table 1. Socio-demographic and economic characteristics, frequency of discriminatory experiences and common mental disorders in students of the Universidade Federal de Santa Catarina. Florianópolis, Santa Catarina, 2012.

\section{Characteristic}

Undergraduate course

\begin{tabular}{l|l}
\hline Accounting & \\
\hline Law & \\
\hline Electric Engineering & \\
\hline Mechanical Engineering & \\
\hline Chemistry Engineering & \\
\hline Sanitary and Enviromental Engineering & \\
\hline History & \\
\hline Medicine & \\
\hline Dentistry & \\
\hline Pedagogy & \\
\hline Psychology & \\
\hline Information Systems & \\
\hline Semester of study &
\end{tabular}

\begin{tabular}{l|l|l}
\hline First & 450 & 40.3 \\
\hline Intermediary & 331 & 32.8 \\
\hline Last & 242 & 26.9
\end{tabular}

Gender**

\begin{tabular}{c|c}
\hline Male & 553 \\
\hline Female & 455 \\
\hline Age (years) & \\
\hline $16-19$ & 307 \\
\hline $20-22$ & 352 \\
\hline $23-27$ & 263 \\
\hline $28-52$ & 75 \\
\hline Color/race & **
\end{tabular}

\begin{tabular}{|c|c|}
\hline 133 & 10.2 \\
\hline 89 & 9.2 \\
\hline 94 & 7.3 \\
\hline 69 & 4.7 \\
\hline 65 & 10.1 \\
\hline 79 & 7.0 \\
\hline 82 & 18.2 \\
\hline 116 & 8.0 \\
\hline 103 & 7.4 \\
\hline 40 & 4.0 \\
\hline 72 & 8.3 \\
\hline
\end{tabular}

5.750 .9

\begin{tabular}{c|c}
553 & 55.7 \\
\hline 455 & 44.3 \\
\hline 307 & 29.6 \\
\hline 352 & 36.1 \\
\hline 263 & 26.4 \\
\hline 75 & 8.0 \\
\hline
\end{tabular}

\begin{tabular}{|c|c|c}
\hline White & 827 & 84.4 \\
\hline Brown & 101 & 10.6 \\
\hline Black & 51 & 5.0 \\
\hline
\end{tabular}

\section{Socioeconomic position (in quintiles)**}

\begin{tabular}{l|c|c}
\hline 1 (poorer) & 202 & 21.9 \\
\hline 2 & 201 & 21.1 \\
\hline 3 & 196 & 20.4 \\
\hline 4 & 193 & 18.5 \\
\hline 5 (richer) & 190 & 18.0 \\
\hline Common mental disorders & 385 & 40.1 \\
\hline Yes & 638 & 59.9 \\
\hline No & & \\
\hline Discrimination & 654 & 65.8 \\
\hline Yes & 369 & 34.2 \\
\hline No & 1,023 & 100.0 \\
\hline Total & & \\
\hline
\end{tabular}

*The percentages are adjusted according to the sampling design and weights; ${ }^{* *}$ variables with $15-44$ missing observations. 
Table 2. Frequency of common mental disorders, according to socio-economic and demographic characteristics, as well as discriminatory experiences of students of the Universidade Federal de Santa Catarina. Florianópolis, Santa Catarina, 2012.

\begin{tabular}{|c|c|c|c|}
\hline \multirow{2}{*}{ Variable } & \multicolumn{3}{|c|}{ Common mental disorder } \\
\hline & $\% *$ & $95 \% \mathrm{Cl}$ & p-value \\
\hline \multicolumn{3}{|l|}{ Undergraduate course } & \multirow{13}{*}{$<0.001$} \\
\hline Accounting & 36.7 & $28.5-45.0$ & \\
\hline Law & 38.7 & $28.1-49.3$ & \\
\hline Electric Engineering & 32.9 & $23.3-42.5$ & \\
\hline Mechanical Engineering & 37.8 & $26.3-49.3$ & \\
\hline Chemistry Engineering & 25.0 & $14.2-35.8$ & \\
\hline Sanitary and Enviromental Engineering & 34.4 & $23.9-45.0$ & \\
\hline History & 59.0 & $48.2-69.7$ & \\
\hline Medicine & 43.3 & $34.2-52.3$ & \\
\hline Dentistry & 30.6 & $21.6-39.6$ & \\
\hline Pedagogy & 47.4 & $31.5-63.2$ & \\
\hline Psychology & 36.6 & $25.6-47.7$ & \\
\hline Information Systems & 40.6 & $28.9-52.2$ & \\
\hline \multicolumn{3}{|l|}{ Semester of study } & \multirow{4}{*}{0.366} \\
\hline First & 39.5 & $29.1-50.9$ & \\
\hline Intermediary & 38.2 & $29.1-48.4$ & \\
\hline Last & 43.2 & $34.8-51.9$ & \\
\hline \multicolumn{3}{|l|}{ Gender } & \multirow{3}{*}{0.472} \\
\hline Male & 39.4 & $31.2-48.3$ & \\
\hline Female & 41.4 & $31.5-52.0$ & \\
\hline \multicolumn{3}{|l|}{ Age (years) } & \multirow{5}{*}{0.366} \\
\hline $16-19$ & 41.8 & $28.5-56.5$ & \\
\hline $20-22$ & 39.9 & $31.4-49.1$ & \\
\hline $23-27$ & 42.9 & $34.5-51.7$ & \\
\hline $28-52$ & 31.4 & $22.7-41.6$ & \\
\hline \multicolumn{3}{|l|}{ Color or race } & \multirow{4}{*}{0.785} \\
\hline White & 40.2 & $31.2-50.0$ & \\
\hline Brown & 42.5 & $28.6-57.7$ & \\
\hline Black & 39.7 & $25.9-55.3$ & \\
\hline \multicolumn{3}{|l|}{ Socioeconomic position (in quintiles) } & \multirow{6}{*}{0.236} \\
\hline 1 (poorer) & 47.0 & $39.6-54.6$ & \\
\hline 2 & 37.5 & $26.5-49.9$ & \\
\hline 3 & 38.6 & $27.2-51.4$ & \\
\hline 4 & 35.8 & $27.8-44.6$ & \\
\hline 5 (richer) & 39.0 & $28.6-50.5$ & \\
\hline \multicolumn{3}{|l|}{ Discrimination } & \multirow{3}{*}{$<0.001$} \\
\hline Yes & 46.7 & $37.9-55.8$ & \\
\hline No & 27.2 & $21.2-34.2$ & \\
\hline
\end{tabular}

${ }^{*}$ The percentages are adjusted according to the sampling design and weights.

$95 \% \mathrm{Cl}: 95 \%$ confidence interval. 
regarding frequency and intensity. Among the individuals with discrimination score equal or superior to 11 , the highest category, the chance of relating common mental disorders was $4.4(95 \% \mathrm{CI} 1.6-12.4)$ times higher than among the non-discriminated ones, even after adjusting for confounding variables.

A statistically significant effect modification was found only in relation to undergraduate course. The probability of having common mental disorders was $57.0 \%$ (95\%CI 49.5 63.4) lower among Electric Engineering students and 2.3 (95\% CI 2.0 - 2.6) times higher among Dentistry ones, when compared to non-discriminated Accounting students. Although having a probability value superior to $5 \%$, the models demonstrate that Brown people have 1.9 (95\% CI $0.4-10.2)$, undergraduates 1.4 (95\%CI $0.8-2.5)$, women 1.3 (95\%IC $0.7-2.4)$ and individuals aged between 23 and 271.2 (95\%CI $0.5-2.6)$ times more chance of developing common mental disorders than their peers. There was an inversion in the direction of association between discrimination and common mental disorders at age between 28 and 52 years $(0.8 ; 95 \% \mathrm{CI} 0.1-6.2)$ and the economic position of the third quintile $(0.7 ; 95 \% \mathrm{CI} 0.3-1.8)$.

\section{DISCUSSION}

The frequency of discriminatory experiences reported among participants was $66.0 \%$, whilst, for common mental disorders, this value was $40.1 \%$. It was observed that those who reported discriminatory experiences had 2.1 (95\%CI 1.6-2.7) times more chance of having common mental disorders, after adjusting for possible confounding factors. The prevalence of common mental disorders increased as students claimed higher frequency and intensity of discriminatory experiences, going from $27.6 \%$ among those who were not discriminated against to $64.9 \%$ among individuals who reported the highest discrimination intensity and

Table 3. Logistic regression models for the association between common mental disorders and discrimination among students of the Universidade Federal de Santa Catarina. Florianópolis, Santa Catarina, 2012.

\begin{tabular}{l|l|c}
\hline Model $^{*}$ & OR & $95 \% \mathrm{Cl}$ \\
\hline $1^{\mathrm{a}}$ & $2.34^{*}$ & $1.81-3.04$ \\
\hline $2^{\mathrm{b}}$ & $2.35^{*}$ & $1.72-3.22$ \\
\hline $3^{\mathrm{c}}$ & $2.32^{*}$ & $1.77-3.06$ \\
\hline $4^{\mathrm{d}}$ & $2.31^{*}$ & $1.75-3.04$ \\
\hline $5^{\mathrm{e}}$ & $2.30^{*}$ & $1.71-3.12$ \\
\hline $6^{\dagger}$ & $2.12^{*}$ & $1.64-2.73$ \\
\hline $7^{\mathrm{9}}$ & $2.11^{*}$ & $1.64-2.71$
\end{tabular}

*The values are adjusted according to the sampling design and weights. a Versus no discriminated; badjusted for color/ race; 'adjusted for "b" and socio-economic status; 'adjusted for "c" and gender; eadjusted for " $d$ " and age; fadjusted for "e" and course; "adjusted for " $\mathrm{f}$ " and the period of the course; OR: odds ratio 


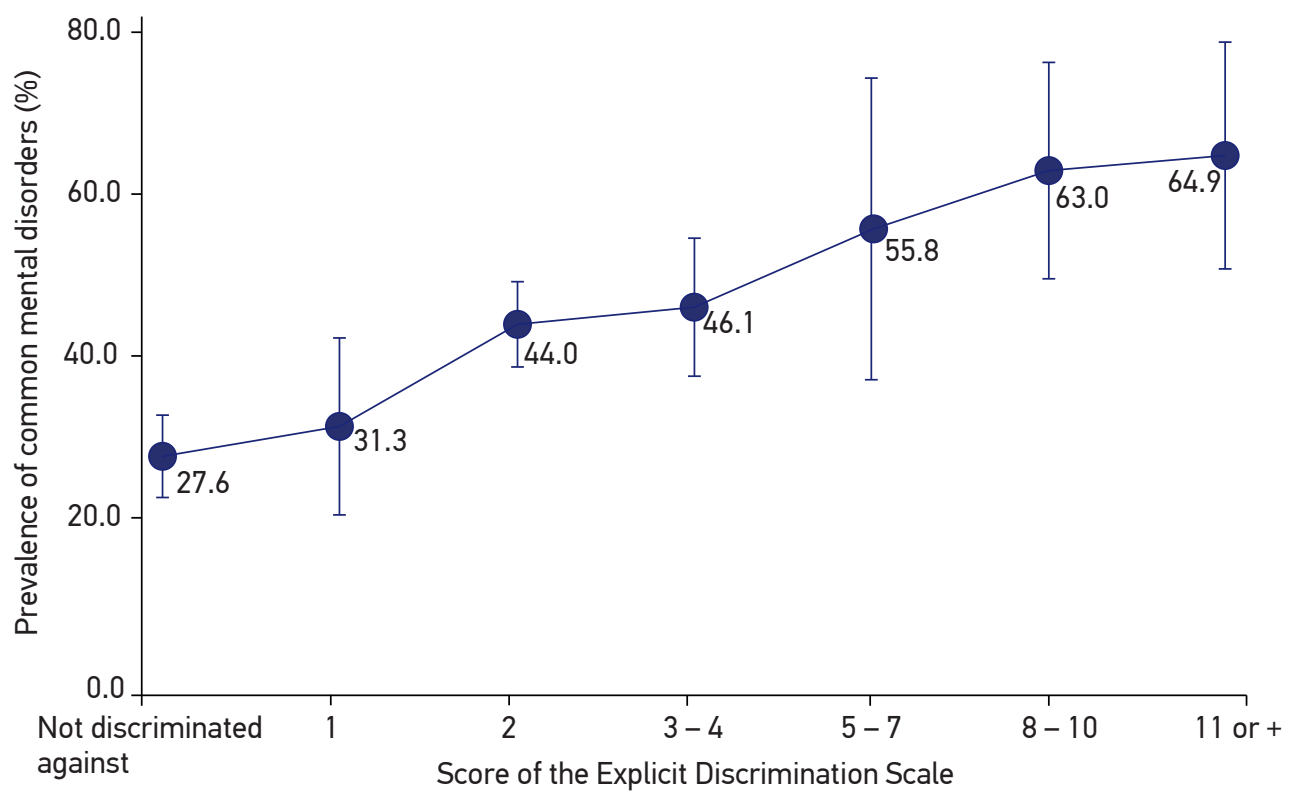

Figure 1. Prevalence of common mental disorders, according to categories of discriminatory experiences adjusted for color/race, socio-economic status, gender, age, course and semester of study at the Universidade Federal de Santa Catarina. Florianópolis, Santa Catarina, 2012.

frequency. Among the individuals in the highest discrimination score category, the odds of reporting common mental disorders was 4.4 (95\%CI 1.6 - 12.4) times higher than among those who were not discriminated against.

The way the constructs of this study were evaluated is an important factor to be considered. The expressive number of questions regarding discrimination and the various domains approached by them may have facilitated the reconstruction of these events, increasing the quality of the answers. Besides, the absence of time limitation in relation to the discriminatory experiences and the use of a self-completed questionnaire may have contributed to the highest report of this kind of event, which was expressively frequent in the investigated population. This last factor may also have influenced the frequency of the outcome, being self-completed, the questionnaire minimized probable fears and embarrassments in reporting both phenomena in direct presence of an interviewer ${ }^{15}$.

The use of an instrument which measures interpersonal discrimination and disregards the remaining levels of the phenomenon, as well as an abbreviated and slightly less precise version of the GHQ in order to measure common mental disorders, stand as limitations of the present study. Besides that, the cross-sectional design does not allow stating the temporal order among the phenomena, not clarifying whether common mental disorders precedes or succeeds the discriminatory experiences at matter. 
Another limitation is in relation to the intersectionality, for, although the study investigates all kinds of discrimination and approaches intersectionality at the moment of measurement of the phenomena, no analysis in order to investigate this aspect directly was performed. It is noteworthy that a previous study, also conducted with Brazilian college students and using the same measuring instruments employed here, already presented results on the intersectionality analysis in discriminatory experiences ${ }^{10}$.

It is noteworthy, also, that discrimination is a complex phenomenon, particularly difficult to evaluate, especially because of its multiple sources and the existence of social rules suppressing it $^{1}$, as it happens in Brazil, where interpersonal discrimination is characterized as subtle. The use of self-completed questionnaires also shows problems related to the measuring of both common mental disorders and discriminatory experiences by being subjective scales, which do not allow further understanding of the events. Not considering the social and contextual nature of the discrimination may result in a simplistic appreciation of the perception of the respondent and, consequently, overestimate the relation between exposure and outcome ${ }^{1}$.

The measure of effect between discrimination and common mental disorders observed in this study, 4.4, was superior to the ones found in previous studies. In a research conducted with indigenous North American people, it was observed that those who had high scores of discrimination had 2.25 times more chance of presenting worse mental health conditions ${ }^{16}$. In turn, when investigating the relation between discrimination and mental health in four different ethnic groups (Caucasian, Black, Mexican and Puerto Ricans) and through the use of five different discrimination instruments, it was possible to observe that the reporting of discriminatory experiences has been associated with the increase of the prevalence of depression among the respondents; in all the combinations analyzed, the chance of having depression increased 2.21 times in comparison to the ones not discriminated against, considering that, in the case of Puerto Ricans, this number goes up to $4.21^{17}$.

The same observation can be made when comparing the studies carried out in the Brazilian context, as the results found by Santana et al. ${ }^{7}$ and Pavão et al. ${ }^{8}$. This difference in the magnitude of the effect may have been a consequence of the exclusive approach of racial discrimination in these previous studies; the fact that the present study allowed the assessment of discrimination according to levels of frequency and intensity, also played a role in finding a stronger association between the phenomena.

Given that the analysis was based on a representative sample, it may be stated that discrimination and common mental disorders are related in the institution. The modification of effect by undergraduate course deserves future investigations. The hypothesis is that this effect modification is a result of the influence of other factors in the causal chain linking discrimination to the outcome, which are, in a way, associated with the undergraduate course. It was not possible to investigate these factors in the present study because of the difficulty in measuring the phenomena and their inclusion in a parsimonious model. This should be better approached by 
future qualitative studies, more capable of dealing with the subjective nature of the phenomena.

We can conclude by the existence of a relation suggestively strong between discrimination and common mental disorders, which reinforces the importance of the discriminatory phenomenon as determinant of health conditions. Differently from most studies on the theme, from North America, as observed in the review by Goto et al. ${ }^{9}$, the present study was conducted in Brazil and it not only confirms the results found by those performed in the US, but also strengthens the generalizability of findings across countries and sociocultural contexts.

\section{CONCLUSION}

The findings suggest that the dose-response relationship between experiences of discrimination and common mental disorders reinforces the hypothetical causal nature of this association. Nevertheless, the modification of effect caused by undergraduate course should be considered in future studies for a better understanding and measurement of both phenomena.

\section{REFERENCES}

1. Correll J, Judd CM, Park B, Wittenbrink B. Measuring prejudice, stereotypes and discrimination. In: Dovidio JF, Hewstone M, Glick P, Esses VM, editors. The SAGE handbook of prejudice, stereotyping and discrimination. London: SAGE; 2010. p. 45-62.

2. Dovidio JF, Hewstone M, Glick P, Esses VM. Prejudice, stereotyping and discrimination: theoretical and empirical overview. In: DovidioJF, Hewstone M, Glick P, Esses VM, editors. The SAGE handbook of prejudice, stereotyping and discrimination. London: SAGE; 2010. p. 3-28.

3. Pascoe EA, Smart Richman L. Perceived discrimination and health: a meta-analytic review. Psychol Bull 2009; 135(4): 531-54.

4. Suija K, Aluoha A, Kalda R, Maaroos HI. Factors associated with recurrent depression: a prospective study in family practice. Family Pract 2011; 28(11): 22-8.

5. Pieterse AL, Neville HA, Tood NR, Carter RT. Perceived racism and mental health among Black American adults: a meta-analytic review. J Couns Psychol 2012; 59(1): 1-9.
6. DaMatta R. Relativizando: uma introdução à antropologia social. Rio de Janeiro: Rocco; 1987.

7. Santana VS, Almeida-Filho N, Roberts R, Cooper SP. Skin colour, perception of racism and depression among adolescents in urban Brazil. Child Adolesc Ment Health 2007; 12(3): 125-31.

8. Pavão AL, Ploubidis GB, Werneck G, Campos MR. Racial discrimination and health in Brazil: evidence from a population-based survey. Ethn Dis 2012; 22(3): 353-9.

9. Goto JB, Couto PF, Bastos JL. Revisão sistemática dos estudos epidemiólogicos sobre discriminação interpessoal e saúde mental. Cad Saúde Pública 2013; 29(3): 445-59.

10. Bastos JL, Barros AJ, Celeste RK, Paradies Y, Faerstein E. Age, class and race discrimination: their interactions and associations with mental health among Brazilian university students. Cad Saúde Pública 2014; 30(1): 175-86. 
11. Bastos JL, Faerstein E, Celeste RK, Barros AJ. Explicit discrimination and health: development and psychometric properties of an assessment instrument. Rev Saúde Pública 2012; 46(2): 269-78.

12. Mari JJ, Williams P. A comparison of the validity of two psychiatric screening questionnaires (GHQ12 and SRQ-20) in Brazil, using Relative Operating Characteristic (ROC) analysis. Psychol Med 1985; 15(3): 651-9.

13. Lopes CS, Faerstein E, Chor D. Stressful life events and common mental disorders: results of the Pro-Saude Study. Cad Saúde Pública 2003; 19(6): 1713-20.

14. Barros AJ, Victora CG. Indicador econômico para o Brasil baseado no censo demográfico de 2000. Rev Saúde Pública 2005; 39(4): 523-9.
15. Fowler FJ. Improving survey questions: design and evaluation. London: SAGE; 1995.

16. Johansson P, Muller CJ, Samos MW, Goldberg J. The influence of perceived discrimination on health-related quality of life in an East Coast American Indian tribe. J Health Care Poor Underserved 2013; 24(4): 1531-41.

17. Benjamins MR. Comparing measures of $\mathrm{racial} / \mathrm{ethnic}$ discrimination, coping, and associations with healthrelated outcomes in a diverse sample. J Urban Health 2013; 90(5): 832-48.

18. Kerner I. Tudo é interseccional? Novos Estud CEBRAP. 2012; 93: 45-58.

Received on: 05/13/2014

Final version presented on: 12/22/2014

Accepted on: 01/12/2015 